\title{
DEPURANDO AS INTERPRETAÇÕES \\ DA KÁTHARSIS NA POÉTICA \\ DE ARISTÓTELES
}

Cláudio William Veloso*

UFM G

Resumo: 0 presente ensaio não propõe a enésima interpretação da catarse na Poética de Aristóteles. Seu objetivo é mais negativo do que positivo. Trata-se sobretudo de denunciar o encarniçamento interpretativo em volta de sua menção na definição da tragédia em Poet. 6. Uma atenção especial é dada a interpretações em língua portuguesa.

Palavras-chave: Aristóteles. Poética. Catarse. Prazer cognitivo. Imitação.

Abstract: The present paper doesn't suggest the nth interpretation of katharsis in Aristotle's Poetics. Its aim is negative rather than positive. Its main point is to denounce the interpretative fierceness around the mention of katharsis in the definition of tragedy in Poet. 6. This paper pays special attention to its interpretations in the Portuguese language.

Key words: Aristotle. Poetics. Catharsis. Cognitive pleasure. Imitation.

\footnotetext{
${ }^{*}$ Uma versão anterior do presente texto foi publicada, sob o mesmo título, em R. DUARTE - V. FIGUEIREDO - V. FREITAS - I. KANGUSSU, (ed.), Kátharsis. Reflexos de um conceito estético, Belo Horizonte, C/Arte, 2002, 70-9. Originalmente o trabalho foi apresentado no Colóquio Internacional Kátharsis (UFMG, Belo Horizonte, 17-20 de Abril de 2001), o que explica o seu tom um tanto informal.
} 

pela descontextualização. Entendo, descontextualização do quadro geral do pensamento aristotélico.

Vale a pena lembrar que na editio princeps das obras de Aristóteles, publicada em Veneza entre 1495 e 1498, a Poética está ausente. De fato, ela só veio a ser publicada, com a Retórica, em 1508, mas - note-se bem - em um corpus de oradores gregos ${ }^{1}$. Generalizando (logo cometendo injustiças), pode-se dizer que a leitura da Poética, do Renascimento até o século XX, ficou relegada a "literatos", que provavelmente pouco ou nada conheciam do resto das obras de Aristóteles ou que, ainda que conhecessem, não a inseriam no contexto do pensamento aristotélico. Por outro lado, os filósofos ou historiadores da filosofia que penetraram as páginas da Poética fizeram-no em geral de maneira um tanto desajeitada. Em ambos os casos, as associações com outros contextos não iam além das Éticas, da Retórica e da Política².

Tal situação favoreceu o surgimento de toda uma série de grandes equívocos, por parte tanto dos "literatos" quanto dos "filósofos". E mesmo a crítica do séc. XX ou, pelo menos, a sua parte melhor, que procurou reconduzir a Poética ao pensamento de Aristóteles, o fez, no mais das vezes, em uma ótica "coerentista" ${ }^{3}$, como se a Poética se limitasse a ser 0 mar de mais uma praia onde lançar a rede conceitual aristotélica. No entanto, a própria colocação da Poética no interior do sistema do saber aristotélico permanece problemática ${ }^{4}$.

Ora, não é alheio a essa descontextualização geral o espaço decididamente excessivo que a questão da kátharsis tomou nos comentários à Poética. Se é legítimo que sua inesperada menção na definição da tragédia desperte nossa curiosidade, de todo insensato me parece o fato de se ter escrito sobre esse assunto uma inteira biblioteca, como diz Ross ${ }^{5}$, e de esse termo se ter tornado o mais conhecido de toda a Poética.

\footnotetext{
${ }^{1}$ Cf. J . IRIGOIN, Tradition et critique des textes grecs, Paris, Les Belles Lettres, 1997, 171.

${ }^{2}$ Ver, por exemplo, a pequena seleção de trechos de autores modernos sobre a Poética, presente em D. LANZA (intr., trad. e note di), Aristotele. Poetica, Milano, Bur, 1987. ${ }_{3}^{3}$ Por exemplo, H. HAEFLIGER, La Poétique d'Aristote. Une synthèse et une intégration dans la méthodologie d'Aristote, Kairos 9 (1997), 97-119.

${ }^{4}$ Cf. D. L. BLACK, Logic and Aristotle's Rhetoric and Poetics in Medieval Arabic Philosophy, Leiden, Brill, 1990, 17-51; P. MORAUX, Les listes anciennes des ouvrages d'Aristote, Louvain, Éditions Universitaires de Louvain, 172-183; C.W. VELOSO, La Poetica: scienza produttiva o logica?, in D. LANZA, (ed.), La Poetica di Aristotele e la sua storia. Atti della Giornata internazionale di studi in memoria di Viviana Cessi, Università degli Studi di Pavia, 22.02.2002, Pisa, ETS, 2003, 93-113.
}

5 D. ROSS, Aristotle, London, Mathuen \& Co, 1953 (1923), 282. 
No texto, a palavra kátharsis aparece apenas duas vezes, isto é, só uma vez mais, além da fatídica aparição no cap. 6. E a segunda, no cap. 17 (1455b 15), onde se refere à prática ritual, é de nenhuma ou pouca ajuda para a compreensão da primeira - e certamente não justificaria a organização de um colóquio internacional. Ficamos, assim, com uma única passagem, a da definição da essência da tragédia. Não custa relê-la:

\begin{abstract}
"Mas falemos da tragédia, tirando 6 , a partir das coisas ditas, a que resulta ser definição da essência desta: tragédia é, então, imitação de uma ação ( práxeos) séria e completa ${ }^{7}$, com um tamanho, em uma linguagem temperada, separadamente para cada uma ${ }^{8}$ das formas nas [suas] partes, [por parte] de [pessoas] que agem (drónton) ${ }^{9}$ e não através de narração, que, através de piedade e medo, leva a cabo a purificação de tais afecções ${ }^{10}$ (peraínousa tèn tôn toioúton pathemáton kátharsin)" (Poet. 6, 1449b 22-28).
\end{abstract}

Embora o cap. 6 abunde em definições, nada mais se dirá a propósito de kátharsis, assim como nada foi dito antes ${ }^{11}$. Como explicar essa omissão? $\mathrm{E}$, principalmente, o que fazer diante dela?

Antes de tudo, é preciso atenuar a solenidade do momento. Temos aí realmente uma definição da essência? Não creio. Se considerarmos Met. Z 17 como o "texto canônico" para o assunto, define a essência aquilo que, segundo um esquema ternário, é causa de y ser $z$, onde y é a matéria e $z$, o composto. Por exemplo, a alma é causa de estas carnes e ossos aqui serem um homem. No caso da tragédia, causa de algo ser uma tragédia é sua capacidade de suscitar o prazer apropriado, a saber, o que provém de

\footnotetext{
${ }^{6}$ Lendo apolabóntes, segundo os manuscritos, e não segundo a correção de Bernays, acol hida por R. KASSEL (recognovit), Aristotelis De Arte Poetica liber, Oxford, Clarendon Press, 1965.

${ }^{7}$ Com base em Poet. 7, 1450b 24 s. (cf. 8, 1451a 31-2; 23, 1459a 20), pode-se supor que na linha 25 falte hóles ('inteira'). Cf. M.D. PETRUSEVSKI, Pathemáton kátharsin ou bien pragmáton systasin?, Ziva Antika 4 (1954), 237-44; 240; resumo em francês do texto publicado nas p. 209-36; ver também a seleção de passagens da Poética nas p. 245-50. ${ }^{8}$ Lendo hekásto(i), segundo Reiz apud Kassel, e não segundo os manuscritos.

${ }^{9}$ Os atores ou as personagens? Parece-me uma alusão ao espetáculo, pois, ao explicar os elementos da definição, Aristóteles pouco depois: "Mas uma vez que produzem a imitação agindo (práttontes), em primeiro lugar, por necessidade, a encenação do espetáculo (ho tês ópseos kósmos) seria uma certa parte da tragédia" (6, 1449b 31-3). Por outro lado, a menção do espetáculo não decorre do que foi dito antes, pois no cap. 3 Aristóteles refere-se sempre a autores e nunca está em questão a enceneção dos textos. Diversamente R. DUPONT-ROC - J . LALLOT (texte, trad., notes par), Aristote. Poétique, Paris, Seuil, 1980, 187; 161.

10 Traduzo pathemáton com 'afecções' provisoriamente.

${ }^{11}$ Aliás, tampouco medo e piedade são mencionados nos capítulos anteriores, mas podemos conceder, com R. DUPONT-ROC - J . LALLOT, Aristote. Poétique, 189, que a relação entre a tragédia e tais emoções fosse um fato conhecido (cf. PLATÃO, Phaedr. 268cd; GÓRGIAS, Hel. 9). Segundo H. HAEFliger, La Poétique d'Aristote, 109-10, ela resultaria das considerações feitas no estudo histórico dos cap. 4-5.
} 
medo e piedade por meio de imitação (Poet. 14, 1453b 1-14). Por conseguinte, a de Poet. 6 é mais uma descrição. Por isso, inclusive, a incongruência relativa à necessidade ou não do espetáculo, o qual aparece inicialmente como parte necessária da definição (1449b 31-3) para ser dispensado em seguida (1450b 15-20). Ora, se a mera leitura-audição da história de Édipo é capaz de desempenhar tal função (cf. Poet. 14), isso será uma tragédia, ainda que não haja espetáculo algum. Assim, o espetáculo não é um definiens, mas um eventual definiendum ou a matéria do mesmo. Pode-se perguntar por que isto (este espetáculo aqui) é uma tragédia, e a resposta será que isso é capaz de suscitar o prazer apropriado. Já mostrei alhures que a suposta divisão da imitação dos cap. 1-3 é, antes, uma "imitação da divisão"12: do mesmo modo, a definição presente no cap. 6 seria uma "imitação de definição".

Seja como for, não vejo nenhuma explicação razoável para a falta de uma "definição" de kátharsis, mas ela pode ser vista à luz do caráter "provisório" do texto que temos ${ }^{13}$. Segundo alguns, Aristóteles teria tratado demoradamente dessa noção em outros lugares, infelizmente perdidos: 0 diálogo Dos poetas ou o segundo livro da Poética. No entanto, com base nas informações que dispomos do Dos poetas, nada nos autoriza a pensar isso. Quanto ao segundo livro da Poética, concordo com Lanza [1987] (p. 20-21) acerca da desnecessidade de supor a sua existência. Aliás, a vexata quaestio da kátharsis e a injustificada certeza da existência do segundo livro estão intimamente ligadas.

Parece-me excessivo, de qualquer forma, o desconsolo expresso por Eudoro de Sousa acerca da omissãa ${ }^{14}$. Essa não é a única nem a mais grave. Por exemplo, Aristóteles não fornece esclarecimento algum sobre aquela que é a noção mais importante do texto, ou seja, a de mímesis. Não obstante, esse termo - ou algum outro membro da família do verbo miméomai - aparece várias vezes, como aparece também em muitos outros textos. E o exame das passagens fora da Poética, não só não é inútil (ao contrário do que alguns comentadores acreditam), mas é mesmo indispensável para uma boa leitura da Poética.

No entanto, não igualmente proveitoso será o exame das aparições de kátharsis e sua família nas outras obras de Aristóteles - coisa, porém, sempre recomendável. Após uma excursão pelas obras biológicas, prova-

\footnotetext{
12 Refiro-me à minha tese de doutoramento, Aristóteles Mimético (São Paulo, USP, 1999), a ser publicada em 2003 pela Discurso Editorial de São Paulo.

${ }^{13}$ Cf. D. LANZA, Aristotele. Poetica, ad locum. Mas acredito que um certo desleixo conceitual (além de formal) caracterize a Poética, o que, pelo menos em parte, talvez explique o estado atual do texto, para além de suas vicissitudes históricas.

${ }^{14}$ E. de SOUSA (Tradução, Prefácio, Introdução, Comentário e Apêndices de), Aristóteles. Poética, Lisboa, Imprensa Nacional-Casa da Moeda, ${ }^{3} 1992,33$.
} 
velmente acabaremos por concentrar nossa atenção naquela outra famigerada passagem, a saber, Pol. VIII 6-7 ${ }^{15}$. Mas aí - para além do fato de em Pol. VIII estar em questão a música (ainda que teatral, cf. 7, 1342a 18) - a coisa toma feições labirínticas, já que nesse ponto a Política remete à Poética: "Mas quanto ao que entendemos por purificação, se agora [0 usamos] de maneira simples (haplôs), na Poética falaremos de novo de maneira mais clara" (7, 1341b 38-41).

Encontramo-nos, então, mais ou menos na mesma situação do leitor que, diante de um termo desconhecido, vai buscar auxílio no dicionário e fica ainda mais desesperado, ao constatar que o verbete - fornecendo, às vezes, um único exemplo - remete justamente à passagem que ele está lendo. Quem tem familiaridade com os textos antigos sabe que isso não é tão raro. A propósito, é claro que consultar os dicionários e léxicos sub vocem kátharsis pode ser útil - possivelmente indo verificar as passagens citadas - mas não acredito que possa remediar a omissão de Aristóteles. (Ao uso do dicionário, aliás, voltarei mais tarde.)

Seja como for, gostaria de fazer duas observações sobre Pol. VIII 7.

Primeira observação. Sem querer examinar a tese do suposto caráter médico de tal purificação ${ }^{16}$, chamo a atenção para o fato de que em 1342a 1011 o termo se encontra simplesmente associado a iatreía ('tratamento', 'cura'). Não sabemos, todavia, se devemos ver tal associação como uma espécie de hendíadis ou se Aristóteles entende coisas diversas, ainda que próximas, ou ainda se o kaí ('e') é explicativo ${ }^{17}$.

Segunda observação. Aristóteles tampouco fala propriamente de uma kátharsis musical - aliás, não vejo muito sentido nessas adjetivações (kátharsis religiosa, médica, trágica etc.), se por elas entendermos necessariamente sentidos diferentes. Após ter usado o termo duas vezes antes da

\footnotetext{
${ }^{15}$ Cf. V. YATES, A sexual model of catharsis, Apeiron 31.1 (1998) 35-57. Segundo Yates, com base em pesquisa feita com o Thesaurus Linguae Graecae, contra as 2 aparições na Poética e as 5 na Política, o termo kátharsis aparece 51 vezes no GA e na $H A$, onde se refere às menstruações das fêmeas, às quais é análoga a emissão de sêmen por parte dos machos (GA IV 5, 774a 1-3; I 20, 728a 26-9; II 3, 737a 28-30; II 7, 746b 24 s.). Apesar de não explicar de maneira simples e satisfatória a presença de kátharsis em Poet. 6, o modelo copulativo-ejaculatório proposto por Yates, no qual a depuração resulta de um processo natural sem estado patológico prévio, não deixa de ser interessante. Para uma visão de conjunto, of. F. REY PUENTE, A kátharsis em Platão e Aristóteles, in R. DUARTE - V. FIGUEIREDO - V. FREITAS - I. KANGUSSU, (ed.), Kátharsis, 10-27. ${ }^{16}$ Cf. J . BERNAYS, Aristotle on the Effect of Tragedy, tr. ingl. de J . \& J . Barnes, em J . BARNES - M. SCHOFIELD - R. SORABJ I, R., (ed.), Articles on Aristotle, 4, Psychology and Aesthetics, London, Duckworth, 1979, 154-65; original em J. BERNAYS, Zwei Abhandlungen über die aristotelische Theorie des Drama, Berlin 1880 (Breslau 1857). Mas lembro que existem outras versões dessa linha interpretativa.

17 Segundo Yates (p. 48), a menção da kátharsis atenua o termo médico.
} 
remissão à Poética, Aristóteles passa a usá-lo com cuidado: "como se tivesse obtido (hósper tykhóntas) um tratamento e uma purificação" (1342a 101); "para todos é necessário que se produza uma certa purificação (tina kátharsin) e um ser aliviado (kouphízesthai) com prazer" (1342a 14-5). Temos aqui dois sintagmas que exprimem de algum modo a imitação. Refiro-me ao hos + particípio (que tem valor subjetivo ou equivale ao nosso 'como se') e ao uso "alienante" do indeterminativo ti, semelhante ao nosso "uma espécie de" para quando não sabemos muito bem como definir algo ${ }^{18}$.

Ora, se na Política Aristóteles fala apenas de "uma espécie de purificação", é possível - mas nada garante - que o mesmo valha para a definição da tragédia, embora aí não haja atenuação alguma. De qualquer forma, como observa Petrusevski (p. 240), Aristóteles condena o recurso a translações e termos inusitados nas definições (Top. VI 1, 139b 32 s.).

A esse ponto, o leitor da Poética deveria render-se e reconhecer a impossibilidade de compreender plenamente 0 sentido da presença de kátharsis no cap. 6 , já que não está nem pré-anunciada nos capítulos anteriores, nem esclarecida nos sucessivos.

$\mathrm{Na}$ verdade, ainda lhe resta uma saída. Pode imaginar que a kátharsis se identifique ou, pelo menos, se refira a uma das noções recorrentes no texto e dignas de figurar na definição da tragédia. Aí vejo um único candidato com chances. É o prazer ${ }^{19}$, que inclusive é mencionado na Política - sem esquecer, no entanto, que 0 alívio é prazeroso apenas por acidente (EN VII $15,1154 b$ 9-20) $)^{20}$.

De fato, o cap. 4 fala de um prazer obtido por meio da imitação (cf. 1448b 8 s.) e ele volta, por exemplo, no cap. 14, onde lemos:

“É possível que o que suscita medo e piedade (tò phoberòn kaì eleeinón) se produza a partir do espetáculo (ópsis), mas é possível também que se produza a partir da composição dos fatos (systáseos tôn pragmáton), o que é justamente prioritário e do poeta melhor. Mesmo sem a visão, é preciso compor a história (mythos) de modo tal que quem escuta os fatos (prágmata) ocorridos trema e tenha piedade, a partir das coisas que acontecem, justamente 0 que se poderia provar escutando a história de Édipo. Proporcionar isso através do espetáculo é alheio à técnica e ligado à produção teatral

\footnotetext{
${ }^{18}$ Cf. PLATÃO, respectivamente, Resp. III 393a s. e X 596e s.

${ }^{19}$ Cf., por exemplo, I. DÜRI NG, Aristoteles. Darstellung und Interpretation seines Denkens, Heidelberg, Carl Winter Universitätverlag, 1966, 162s.

20 Tal seria o prazer da ejaculação dos machos, análoga à menstruação nas fêmeas, segundo o modelo sexual de Yates (p. 47-8). Na medida em que é algo que sobrevém a uma atividade ( $E N \times 4,1174 b 20-1$ ), por si o prazer propriamente seria sempre cognitivo, ou seja, perceptivo ou intelectivo. A tal propósito, remeto ao meu ensaio, já mencionado, «a Poetica: scienza produttiva o logica?», p. 111s.
} 
(khoregía). Os que proporcionam pelo espetáculo não o que suscita medo, mas apenas 0 monstruoso, não partilham em nada da tragédia. Com efeito, não se deve buscar, a partir da tragédia, todo prazer, mas o apropriado (oikeîa). Uma vez que o poeta deve proporcionar o prazer a partir da piedade e do medo por meio da imitação, é evidente que é preciso que isso se engendre nos fatos (prágmasin)" (Poet. 14, 1453b 1-14).

A passagem inegavelmente evoca a definição da tragédia. Além do mais, a identificação ou referência ao prazer tem a vantagem de instituir algum pré-anúncio nos capítulos anteriores ao sexto - o que é importante, visto que, como o próprio texto sugere, eles deveriam fornecer a base para a definição da tragédia. E acho altamente improvável que Aristóteles aí se refira a Pol. VIII 7, como sugere Donini ${ }^{21}$.

É verdade que, no exame da definição da tragédia de Poet. 6, estou deixando de lado algumas questões pertinentes:

1. o exato significado do verbo peraíno, que rege kátharsinin ${ }^{22}$;

2. o valor do genitivo da expressão tôn toioúton pathemáton que qualifica kátharsis, ou seja, se é subjetivo ou objetivo, ou ainda separativo;

3. o sentido de toioûton, ou seja, se deve ser entendido como "de tal gênero" ou como um mero demonstrativo;

4. enfim, o significado de páthema: aliás, a lição pathemáton (fornecida pelo manuscrito $B$, o Riccardianus 46 , e confirmada pelo fragmento da tradução síria e pela tradução árabe) é provavelmente a melhor.

Por outro lado, julgo difícil chegar a uma resposta definitiva sobre esses pontos sem ter previamente, pelo menos de maneira implícita, estabelecido o significado de kátharsin.

A propósito de páthema, eu teria, na verdade, algo a dizer. Para além da possível distinção entre páthos e páthema (entendido como uma afecção crônica), o termo pode significar também 'fato', 'acontecimento'(Cf. Poet. 24, 1459b 11) ${ }^{23}$. É assim, por exemplo, em De inter. 1. Os "pathémata na alma" de 16a 3-4 - aos quais corresponderiam "as coisas que estão na voz" - decerto não se reduzem a emoções ou paixões, mas indicam, generica-

\footnotetext{
${ }^{21}$ Cf. P. DONINI, La tragedia senza la catarsi, Phronesis 43/1 (1998) 26-41.

22 Parece-me, em todo caso, exagerada a conclusão que Donini (p. 32s.) acredita poder tirar daí, ou seja, que a tragédia apenas completa a catarse musical das paixões. Com efeito, segundo Donini, na definição o verbo peraíno não teria o sentido genérico de "produzir do início ao fim" - que, aliás, ele apresenta três linhas depois (1449b 30) -, mas o de concluir algo já iniciado (cf. PLATÃO, Prot. 353b), pelo sujeito ou por outros. Em todo caso, o contexto definitório não deveria suportar grandes sutilezas.

${ }^{23}$ Cf. A. NEHAMAS, Pity and Fear in the Rhetoric and the Poetics, in A.O. RORTY (ed.), Essays on Aristotle's Poetics, Princeton, Princeton University Press, 1992, 291-313; 307; V. YATES, A sexual model of catharsis, 52-3.
} 
mente, tudo aquilo que acontece nela ${ }^{24}$. Assim, pathémata pode ser sinônimo de prágmata, o que aproxima ainda mais a definição da tragédia da passagem do cap. 14.

Aqui eu me daria por satisfeito. Quero dizer que, se eu devesse fazer uma tradução da Poética - como talvez um dia faça - não escreveria, na nota à kátharsis do cap. 6 , muito mais do que disse até agora. Com isso não quero dizer que a noção de kátharsis não é algo importante na Poética, pois para tal deveria saber o que ele aí significa com exatidão, o que justamente não está claro.

Bem entendido, não acabo de propor elementos para uma interpretação da "catarse trágica". Apenas admiti que a noção designada pelo termo kátharsis em Poet. 6 talvez se identifique ou esteja relacionada com a noção designada pelo termo hedoné, 'prazer'25, ainda que não saiba exatamente como. $M$ ais do que isso, na falta de elementos novos, acredito, pace Donini (p. 32), que não se possa e não se deva fazer.

Não obstante, não é o que normalmente se fez. Uma montanha de interpretações mirabolantes surgiu em cima dessa única menção. E não me parece temerário afirmar que ao "caso kátharsis" muito deve ter contribuído o neoplatonismo. Baste ler as passagens de Proclo (V d.C.) e Jâmblico (III-IV d.C.) incluídas nos fragmentos do Dos poetas (frag. 5 Ross) - aliás, como observa Lanza [1987] (p. 237; cf. p. 61-2), elas estão aí por nenhuma outra razão senão pela infundada convicção de que o diálogo perdido falasse da kátharsis. Em todo caso, eu não quero tratar da história dessas interpretações. Prefiro pôr em confronto dois textos em língua portuguesa sobre 0 assunto, que casualmente encontrei.

Começo pelo mais recente: Kátharsis poética em Aristóteles de Marco Zingano ${ }^{26}$. 0 autor começa lembrando que "a literatura em língua portuguesa a respeito da célebre questão sobre o sentido da noção aristotélica de kátharsis, que fez correr tanta tinta em tantas línguas, é bastante modesta, pelo menos do ponto de vista quantitativo" (p. 37). Ele logo concede (não sem ironia) que a literatura em língua portuguesa teve, no entanto, momentos de alta ousadia, referindo-se à obra de António Freire, A Catarse em Aristóteles ${ }^{27}$. Zingano observa que ela é "altamente instrutiva pelos erros que contém".

Eis um breve resumo da posição de Freire.

No lugar da expressão pathemáton kátharsin, o manuscrito A (Parisinus 1741) - assim como o manuscrito (perdido) a partir do qual Guilherme de

\footnotetext{
24 Igualmente em DA I 1, 403 a 3 s. Cf. PLATÃO, Resp. II 382b; Pol. 270d. O verbo peraíno é usado por Platão para a narração de fatos passados, presentes e futuros (Resp. III 392d).

25 Diversamente P. DONINI, La tragedia senza la catarsi, 35.

${ }^{26}$ Síntese 76 (1997) 37-55.

27 Braga, APPACDM, 1982.
} 
Moerbeke fez sua tradução latina - traz a lição mathemáton kátharsin ('purificação de ensinamentos'). Ambas as lições são obscuras, de modo que poderiam ser substituídas por uma mais provável, a saber, pragmáton systasin, 'composição de fatos'. E isso explicaria a razão pela qual Aristóteles não define a kátharsis: ela simplesmente não aparece na definição da tragédia. Aí deveríamos ler, então, "que termina a composição dos fatos pelo medo e piedade" (cf. p. 34-6).

Freire não reivindica a autoria da tese, que ele expressamente toma de Petrusevski. 0 estudioso português pretende, contudo, ir mais além do que o iugoslavo, fazendo ressaltar os absurdos ideológicos contidos na catarse supostamente existente na definição da tragédia (p. 42).

Concordo com Zingano que a de Freire-Petrusevski está longe de ser uma solução, na medida em que é totalmente arbitrário substituir a expressão por uma outra com o mesmo número de letras, ainda que esta - no caso, pragmáton systasin - tenha a indiscutível vantagem de ser algo bem documentado e importante na Poética ${ }^{28}$. De resto, além de arbitrária, essa substituição é, pelo menos em parte, inútil, visto que pathemáton pode equivaler a pragmáton.

Não encontram meu consenso, todavia, as reservas de Zingano quanto ao possível recurso ao cap. 14:

"Além disto, o início do capítulo 14 não pode fornecer o que seria a expressão original da definição da tragédia no capítulo 6 . No capítulo 14, Aristóteles argumenta que 0 bom poeta obtém os sentimentos de piedade e medo não meramente por efeito cênico, o que sempre pode fazer, mas sobretudo pela "composição dos fatos", isto é, pelo enredo mesmo da peça. Este último procedimento é o mais digno da grande tragédia. Trata-se de uma observação sobre o melhor modo de obter os sentimentos. No capítulo 6, trata-se, ao contrário, de avaliar, na definição mesma da tragédia, o papel que os sentimentos de piedade e medo têm na imitação trágica, qualquer que seja seu modo de obtenção e independentemente da qualidade obtida" (p. 39).

É verdade que Poet. 14 trata dos modos de produzir os fatos que suscitam piedade e medo, e não da definição da tragédia, mas Aristóteles parece fundamentar sua recomendação com base naquilo mesmo que a tragédia seria em sua essência ${ }^{29}$. De qualquer forma, Poet. 14 deixa bem claro que o prazer apropriado à tragédia é aquele ligado aos fatos que suscitam

\footnotetext{
${ }^{28} \mathrm{Não}$ obstante, os argumentos do comentador iugoslavo também estão longe de ser ingênuos. Não sem razão, por exemplo, ele (cf. p. 240s.) insiste nas "imperfeições" da definição da tragédia de Poet. 6 . De qualquer forma, parece-me excessivo dizer, como faz Zingano, que: "Do ponto de vista filológico, a argumentação a propósito da adulteração por um copista atilado tem todas as virtudes que o roubo possui sobre o trabalho honesto, para parafrasear Russell" (p. 39).

${ }^{29}$ Além do mais, os cap. 13-14 são relativamente "caprichados".
} 
piedade e medo, de modo que não haveria nenhum outro papel para piedade e medo na imitação trágica, diversamente do que propõe Zingano (ibidem).

Acontece que Zingano inverte as coisas. Ele considera que a definição da tragédia no fatídico ponto já está perfeitamente clara. Só em virtude disso, ele pode afirmar que a situação do cap. 6 não é a mesma do cap. 14. Ora, mas é justamente 0 sentido desse ponto da definição da tragédia, no cap. 6 , que carece de explicação.

É bom esclarecer uma vez por todas um ponto preliminar. Que estranho prazer seria esse, 0 da função da tragédia (cf. Poet. 26, 1462b 12-4), que vem do medo e da piedade, se em Retórica II ambos são definidos como dores ${ }^{30}$ ? Haveria aí um paradoxo, como sugerem Dupont-Roc e Lallot ( $p$. 189)?

Não. Por isso, não há necessidade de nenhuma "alquimia mimética" - para retomar uma outra expressão de Dupont-Roc e Lallot - para transformar dores em prazeres. A coisa, na verdade, é simples. 0 prazer apropriado à tragédia não está no medo e na piedade ${ }^{31}$. A frase "proporcionar 0 prazer a partir de medo e piedade" seria, antes, uma forma elíptica para "proporcionar o prazer a partir de fatos que suscitam medo e piedade" (cf. 19, 1456b 3-4) ${ }^{32}$. Ou melhor, a partir da imitação desses fatos. Como diz Aristóteles, "não só de uma ação completa é a imitação, mas também de fatos que suscitam medo e que suscitam piedade (phoberôn kaì eleeinôn)" (Poet. 9, 1452a 2-4; cf. 13, 1452b 32-3).

0 prazer em questão não pode ser diferente do prazer abordado no cap. 4. Trata-se do prazer cognitivo, que consiste, por assim dizer, no reconhecimento, diante de um mímema, daquilo de que o mímema é mímema (cf. Top. VI 2, 140a 18-22). Ao contrário do que acredita Zingano (p. 54) $)^{33}$, a fórmula "esse é aquele" não tem nada de elementar. E deve valer mesmo para aquela que seria a forma mais elevada de poesia, a tragédia. 0 prazer proporcionado pela imitação trágica reside no reconhecimento do que suscita medo e piedade, isto é, do phoberón e do eleeinón - o que, aliás, verossi-

\footnotetext{
${ }^{30} \mathrm{Cf}$. respectivamente $R$ het. II 5 e 8.

${ }^{31}$ Que no caso do ouvinte-espectador da tragédia não passam, num certo sentido, de pseudo-emoções, como observa S. KLIMIS, Le statut du mythe dans la Poétique d'A ristote. Les fondaments philosophiques de la tragédie, Bruxelles, Ousia, 1997, 145-6.

32 Mas o prazer não é produto de técnica alguma (EN VII 12, 1152b 18).

${ }^{33} \mathrm{Na}$ trilha de J. LEAR, Katharsis, in A.O. RORTY (ed.), Essays on Aristotle's Poetics, 315-40; 322. Para uma leitura próxima da minha, ver M.C. NUSSBAUM, The fragility of goodness. Luck and ethics in greek tragedy and philosophy, Cambridge, Cambridge University Press, 1990, 388; sed 310s.

${ }^{34}$ Quanto à necessidade do término, cf. M.D. PETRUSEVSKI, Pathemáton kátharsin ou bien pragmáton systasin?, 238. Ver também D. GALLOP, Animals in the Poetics, Oxford Studies in Ancient Philosophy 8 (1990) 145-71; 158s.
} 
milmente só é possível uma vez terminada a história ${ }^{34}$. E estes são fatos, não sentimentos. Prova-se prazer em reconhecer, diante daquele mímema que é a tragédia, os fatos que julgamos efetivamente capazes de suscitar dores como piedade e medo, o que implica a compreensão da seriedade da ação em questão ${ }^{35}$. Mas os fatos da tragédia não são nem phoberoí nem eleeinói, pois nem mesmo são 'fatos', senão por homonímia. Nesse sentido, tampouco podemos dizer que uma tragédia é séria: séria é a ação que ela imita.

Em suma, não há prazer algum no medo e na piedade, pelo menos não sob o mesmo aspecto, mas há prazer em reconhecer aquilo que se julga amedrontador e digno de compaixão. De resto, se função ou fim da tragédia fosse suscitar medo e piedade, ela simplesmente seria uma oratória, e a Poética se reduziria à Retórica.

Quanto sustento encontra confirmação em $D A$ III 3, onde se distingue da opinião (dóxa) a representação ou aparição (phantasía) - segundo o sentido não metafórico, como será precisado em 428a. Recorrendo ao costumeiro exemplo pictórico, o mesmo muitas vezes usado na Poética, Aristóteles escreve:
"Essa afecção, com efeito, depende de nós - pois quando queremos, é pos- sível produzir [uma aparição] diante dos olhos, como aqueles que nas téc- nicas mnemônicas colocam [diante dos olhos] e produzem simulacros -, enquanto ter uma opinião não depende de nós, pois é necessário estar no falso ou no verdadeiro. Ademais, quando reputamos (doxázomen) algo terrível ou temível, provamos imediatamente a afecção, e do mesmo modo se for encorajante. Mas, segundo a aparição (katà tèn phantasían), estamos como aqueles que contemplam em uma pintura as coisas terríveis e encorajantes" (DA III 3, 427b 17-24) ${ }^{36}$.

Pace Klimis (p. 165), não vejo contradição entre essa passagem e a Poética. Aristóteles não está descrevendo uma alternativa, isto é, ou temos uma aparição ou temos uma opinião. Pelo contrário, é impossível, para Aristóteles, que se tenha opinião sobre algo sem uma aparição desse algo, já que não se pensa sem aparições (DA III 7, 431a 14-17). E a "impassibilidade" diz respeito apenas ao reconhecimento - por parte do intelecto, mas através de uma aparição, comparada a uma imitação como seria a pintura - disso que se julga ser temível. Como diz o próprio Aristóteles, pode-se pensar algo de amedrontador mesmo sem ser impelido a fugir, o que não impede que o coração bata mais forte (DA III 9, 432b 29; De motu 11, 703b2-704a 2).

\footnotetext{
${ }^{35}$ Cf. M.C. NUSSBAUM, The fragility of goodness, 390.

${ }^{36}$ Edição do texto grego usada: A. J ANNONE (texte établi par) - E. BARBOTIN (trad. et notes de), Aristote. De l'âme, Paris, Les Belles Lettres, 1989 (1966).
} 
Mas há ainda que esclarecer uma última coisa. Poet. 4 fala certamente de um prazer de natureza cognitiva, mas - note-se bem - a imitação não é conhecimento. Isso fica claro, aliás, no doublet de Poet. 4 presente em Rhet. I 11, onde se precisa que a imitação é algo semelhante ao conhecimento (1371b 5 s.). Aristóteles concebe duas faculdades cognitivas propriamente ditas: a perceptiva e a intelectiva (DA III 9 432a 15-6). Ora, a imitação não é nem percepção nem intelecção. A imitação seria, antes, uma inesperada solução (ou melhor, "uma espécie de solução") para um problema que atravessa toda a gnosiologia aristotélica, do Órganon aos Parva naturalia, passando pelo De anima. Trata-se do "hiato" que haveria entre percepção e intelecção ${ }^{37}$.

Mas voltemos a Zingano. A solução por ele defendida seria a de entender o termo kátharsis não em sua "acepção médica", nem em sua "acepção religiosa", e sim no sentido de "clarificação de um problema", "explanação de uma questão". Desse modo, acredita Zingano, se ofereceria da "kátharsis poética" uma interpretação "compatível com a doutrina aristotélica das emoções" (p. 37). Mesmo não fazendo referência a predecessores, Zingano insere-se, assim, em uma linha interpretativa bem conhecida dos especialistas. Seus maiores representantes são provavelmente Golden ${ }^{38}$ e, em tempos mais recentes, Nussbaum (p. 389-390). Para bem da verdade, se, no tocante à acepção do termo kátharsis, Zingano seguiria Golden, no tocante à doutrina das emoções, ele estaria próximo, antes, de Nussbaum, já que Golden insiste simplesmente no prazer intelectual de Poet. 4. Mas Zingano, em meu entender, comete o mesmo erro metodológico de Golden. Refirome à suposta fonte a partir da qual ele acredita ser possível entender kátharsis como 'clarificação'. Zingano cita o Greek-English Lexikon de Liddell-Scott-Jones, e sem mesmo mencionar os autores aí indicados como exemplos de tal uso - coisa que Golden faz.

Em todo caso, os autores citados pelo Greek-English Lexikon de LiddellScott-Jones são apenas dois: Epicuro (IV-III a.C.) e seu comentador Filodemo (II-I a.C.), ou seja, autores posteriores a Aristóteles. Filodemo é, aliás, posterior de alguns séculos, razão pela qual me sinto dispensado de comentar a passagem do seu Perì parrhesías (Lib. dic. 22, 46, 4-5 Olivieri). Quanto à Carta a Pítocles de Epicuro - conservada, em todo caso, em Diógenes Laércio (III d.C.?) - tenho dúvidas de que physikôn problemáton kátharsin (X 86) signifique realmente "clarificação dos problemas acerca da natureza".

${ }^{37}$ A tal propósito, remeto aos meus artigos «l problema dell'imitare in Aristotele», Quaderni Urbinati di Cultura Classica 65 (2000), 63-97; cf. p. 81; «Phantasia et mimesis chez Aristote», Revue des Études Anciennes 106 (2004), a ser publicado.

${ }^{38}$ L. GOLDEN, The clarification theory, Hermes 104 (1976) 437-452; republicado em M. LUSERKE, (ed.), Die Aristotelische Katharsis. Dokumente ihrer Deutung im 19. und 20. J ahrhundert, Hildesheim-Zürich-New York, Georg Olms Verlag, 1991, 386-401. Golden traça, inclusive, um breve histórico dessa interpretação. 
Ora, segundo Epicuro, no conhecimento não se deve ter outro fim senão a imperturbabilidade e convicção estável, como está dito um pouco antes na mesma carta (85). Para Epicuro o problema seria o próprio problema. Com physikôn problemáton kátharsis Epicuro pode querer dizer "a eliminação [e não propriamente a soluçãa ${ }^{39}$ ] dos problemas acerca da natureza", onde 0 genitivo teria valor objetivo. E o mesmo valeria para o uso de ekkathaíro mais adiante $(87,4)$.

É verdade que certos empregos da família de kathaíro nos séculos V-IV a.C. parecem sugerir a idéia de clareza (intelectual), mas, pelo que me consta, se trata do adjetivo e do advérbio, não do substantivo, senão de maneira "metafórica"40. De qualquer forma, não me parece legítimo afirmar, como faz Nussbaum (p. 389), que seu uso "epistemológico" se tinha tornado normal na época de Aristóteles.

Em outras palavras, não haveria nenhum elemento seguro para um sentido de clarificação. E ainda que fosse possível ler kátharsis como 'esclarecimento' em Poet. 6 , páthema pode significar 'fato', de modo que a tragédia levaria a cabo o "esclarecimento de tais fatos".

Por outro lado, o fim que Zingano se dá com sua interpretação da kátharsis - a saber, compatibilizá-la com a doutrina aristotélica das emoções - revelou-se inútil, na medida em que a tragédia não passa de uma imitação de fatos capazes de suscitar medo e piedade, por meio da qual provamos 0 prazer de reconhecer esses mesmos fatos.

Endereço do autor:

Rua Coletor Celso Werneck, 154 / 410

30350-010 Belo Horizonte (MG)

E-mail: cwveloso@hotmail.com

39 Assim G. ARRIGHETTI, (ed.), Epicuro. Opere, Torino, Einaudi, 1973 (1960); e M. CONCHE, (texte établi et traduit avec une introduction et des notes), Épicure. Lettres et Maximes, Paris, PUF, 2002 (1987).

40 Por ex. ARISTÓFANES Av. 591; Vesp. 631, 1046: katharôs; EURÍPIDES (?), Rh. 35 : katharôs; XENOFONTE, Cyr. 8.7.20: katharós; PLATÃO: Phaed. 66d 8, 66e 5: katharôs; Crat. 426b: katharótata. ARISTÓTELES: An. pr. I 44, 50a 40: katharôs; Rhet. I 2, 1356b 27: katharôs; Rhet. III 12, 1414a 14: kathará (= akribés; cf. PLATÃO, Phaed. 65e-66a; ISÓCRATES, Philippus 4). O uso de kátharsis no Fédon (69c: kátharsís tis) e Sofista (230c-d) não passa de uma metáfora, como observa Donini (p. 30, n. 17); diversamente Rey Puente, p. 12s. 